Reprod. Nutr. Dévelop., 1988, 28 (1), 117-118.

\title{
Influence de la nature de I'aliment concentré sur quelques paramètres de la digestion dans le rumen
}

Sylvie GIGER, D. SAUVANT, Michelle DURAND (*), J. HERVIEU

Station de Nutrition et Alimentation (I.N.R.A.) de I\%.N.A.-PG, 16, rue Claude Bernard, 75231 Paris Cedex 05.

(*) Station de Recherches de Nutrition,

I.N.R.A., 78350 Jouy-en-Josas.

Summary. Carbohydrate composition of concentrates can influence ruminal digestion parameters. The impact on $\mathrm{pH}$ is very important for concentrates rich in highly degradable cell-wall or cereal constituents and less marked for poorly digestible fibre feed. The diet also influences the molar proportion of the different fatty acids.

Les études, conduites à la Station depuis 1979, ont montré que des aliments concentrés de même digestibilité peuvent être formulés avec des constituants riches en amidon ou en parois très digestibles (Giger et al., 1987). Ces derniers se dégradent plus lentement dans le rumen (Sauvant et al., 1985) et pourraient être mieux adaptés aux ruminants laitiers (De Visser, 1981). Cependant, des concentrés riches en parois peuvent également présenter des valeurs énergétiques médiocres. L'objet du présent travail est de préciser l'influence de ces différents types de concentré, dont la cinétique de dégradation in sacco de la matière sèche et des parois est connue (Sauvant et al., 1985) sur les paramètres de la digestion dans le rumen au cours des premières heures post-prandiales.

Matériel et méthodes. L'expérience a été conduite sur des chèvres adultes taries, porteuses d'un trocart ruminal. La ration était constituée par du foin de luzerne distribué seul ( $F L$ ) ou en association avec l'un des trois concentrés. Le niveau de matière sèche ingérée (MSI) est limité à $50 \mathrm{~g} / \mathrm{kg}$ de $P^{0,75}$, et le concentré représente environ $45 \%$ de la MSI. Deux des concentrés ( $A$ et $R$ ) ont été formulés pour présenter une digestibilité de la matière organique (dMO) de $83 \%$, confirmée par mesure in vivo (A : 84.6, $\mathrm{R}: 83.2$ ). Le concentré A est essentiellement constitué de céréales: orge $(30 \%)$, blé $(20 \%)$, son fin $(15 \%)$, avoine $(10 \%)$, tandis que le concentré $\mathrm{R}$ contient une forte proportion de matières premières riches en paroi très digestible : pulpe de betteraves $(30 \%)$, coques de soja $(20 \%)$, pulpe d'agrumes $(10 \%)$, lupin $(10 \%)$. Le troisième concentré (P) présente une teneur en cellulose brute équivalente au concentré $R(16,7$ vs 16,2), mais une dMO, beaucoup plus faible : 65,8\%. Il contient en particulier de la luzerne déshydratée $(30 \%)$, du son fin $(30 \%)$ et de la pulpe de raisin $(10 \%)$.

Les paramètres de la digestion dans le rumen ont été mesurés sur les échantillons prélevés $1,2,3$ et $4 \mathrm{~h}$ après la distribution du foin et de l'aliment concentré du matin (fig. 1). Les données relatives au $\mathrm{pH}$ et aux teneurs en acides gras volatils (AGV), concernent les prélèvements effectués 3 et $4 \mathrm{~h}$ après le repas, ce qui reflète au mieux l'intensité des fermentations (tabl. 1). Pour chacun des régimes, cinq mesures répétées deux jours consécutifs ont été effectuées. Outre l'effet lié au régime, l'influence de la quantité moyenne d'eau bue entre les temps 0 et $4 \mathrm{~h}$ (Eau) a été testée comme covariable.

Résultats et discussion. Les résultats obtenus sont récapitulés dans le tableau 1. D'une façon générale, l'effet du régime est significatif sur le $\mathrm{pH}$ : par rapport au foin seul, les concentrés $A$ et $R$ diminuent significativement le $\mathrm{pH}$ 
FIG. 1. - Evolution du $p H$ ruminal pendant les $4 \mathrm{~h}$ post prandiales.

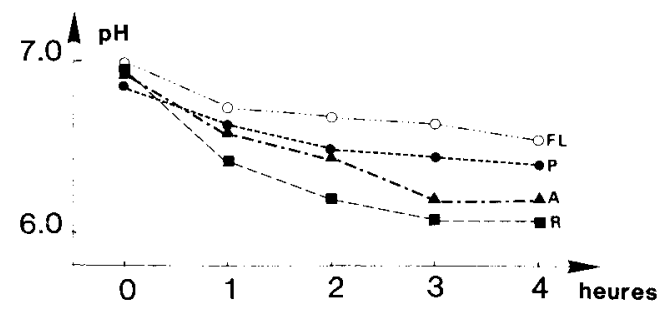

TABL. 1. - Influence de la nature du concentré sur des paramètres de la digestion ruminale : valeurs moyennes des prélèvements effectués 3 et $4 \mathrm{~h}$ après la distribution des aliments.

\begin{tabular}{|c|c|c|c|c|c|c|}
\hline & \multirow{2}{*}{ Régime } & \multirow{2}{*}{ Eau } & \multirow{2}{*}{$\begin{array}{l}\text { Foin } \\
\text { seul }\end{array}$} & \multicolumn{3}{|c|}{ Foin + concentré } \\
\hline & & & & A & $\mathrm{R}$ & $P$ \\
\hline $\mathrm{pH}$ & + & NS & $6,53^{a}$ & $6,12^{b}$ & $6,10^{b}$ & $6,33^{a, b}$ \\
\hline AGV (mmoles $/ 100 \mathrm{ml}$ jus filtré) & ++ & + & $11,4^{\mathrm{a}}$ & $14,1^{\mathrm{a}}$ & $17,4^{b}$ & $13,4^{a}$ \\
\hline Acétique ( $\%$ molaire) & + & NS & $68,0^{\mathrm{a}}$ & $64,0^{\mathrm{b}}$ & $66,7^{a}$ & $65,7 \mathrm{a}, \mathrm{c}$ \\
\hline Propionique ( $\%$ molaire) & ++ & ++ & $20,4^{a}$ & $19,4^{a}$ & $21,8^{b}$ & $20,0^{a}$ \\
\hline Butyrique ( $\%$ molaire) & ++ & NS & $5,2^{a}$ & $10,3^{b}$ & $6,2^{\mathrm{a}, \mathrm{c}}$ & $7,6^{c}$ \\
\hline
\end{tabular}

Les valeurs affectées de la même lettre ne sont pas statistiquement différentes. Niveau de signification : $5 \%+, 1 \%++$.

(- 0,4 point), alors que la baisse observée avec $P$ n'est pas significative. La présence d'un aliment concentré augmente la teneur en AGV du jus de rumen, la différence n'étant significative que pour le concentré $R$. Les trois concentrés n'ont pas le même effet sur le pourcentage molaire des trois principaux AGV : le concentré $A$ ne modifie pas celui en acide propionique, mais augmente très significativement l'acide butyrique et diminue l'acide acétique. Les concentrés $P$ et $R$ ne diminuent pas significativement le pourcentage molaire d'acétate, mais on observe une légère augmentation du butyrate dans le cas du concentré $P$, et du propionate dans celui de $R$. Ces résultats sont proches de ceux obtenus sur moutons, si on compare le concentré $A$ (riche en céréales) à l'orge, et le $\mathrm{R}$ aux pulpes de betteraves étudiées par Berge et Dulphy (1985). II importe de noter que, dans le cas présent, la nature du concentré n'influe pas sur le rapport lacétique + butyrique/propionique), contrairement aux observations faites sur ovins ou bovins par Sutton (1986). La chute de pH et les activités fermentaires intenses observées avec le concentré $R$, à une période où ce sont essentiellement les constituants du contenu cellulaire qui sont dégradés, peuvent s'expliquer par la présence de matières premières riches en pectines comme les pulpes d'agrumes et de betteraves. La quantité d'eau bue a une influence négative sur la teneur en AGV présente, ce qui montre l'effet de cette variable sur la dilution du jus de rumen.

II apparaît donc que le concentré riche en parois très digestibles dont la matière sèche se dégrade plus lentement in sacco que le concentré riche en céréales (Sauvant et al., 1985), peut induire, dans les heures qui suivent le repas, des baisses de $\mathrm{pH}$ qui peuvent se répercuter sur l'activité cellulolytique du rumen.

Berge Ph., Dulphy J. P., 1985. Ann. Zootech., 34, 313-334.

De Visser H., 1981. Bedrifisontwikkeling, 11, 1041-1046.

Giger S., Sauvant D., Hervieu J., 1987. Reprod. Nutr. Dévelop., 27, 201-202.

Sauvant D., Bertrand D., Giger S., 1985. Anim. Feed. Sci. Technol., 13, 7-23.

Sutton J. D., 1986. Proc. Seminar CEE, 1986/06/25-27, Foulum (Danemark), 21-38. 